\title{
miR-215 promotes cell migration and invasion of gastric cancer cell lines by targeting FOXO1
}

\author{
Y. ZANG ${ }^{1, *}$, T. WANG ${ }^{2, *}$ J. PAN ${ }^{1}$, F. GAO ${ }^{3, *}$ \\ ${ }^{1} 1$ Department of Gastroenterology, Taishan Hospital of Shandong Province, Taian 271000, Shandong Province, P.R. China; ${ }^{2}$ Department of \\ Gastroenterology, The Third People Hospital of Jinan, Jinan 250132, Shandong Province, P.R. China; ${ }^{3}$ Department of general surgery, The 88th \\ Hospital of Chinese PLA, Taian 271000, Shandong Province, P.R. China.
}

${ }^{*}$ Correspondence: gaofengmed@sina.com

${ }^{*}$ Contributed equally to this work.

Received November 10, 2016/ Accepted February 8, 2017

\begin{abstract}
Gastric cancer is one of the most common malignant tumor worldwide and has high morbidity and mortality. microRNAs are small, non-coding RNAs which play critical roles in the post-transcriptional regulation of gene expression. In this current study, we used qRT-PCR to detect miR-215 and FOXO1 expression level in 50 paired gastric cancer tissues and found that miR-215 was frequently overexpressed and FOXO1 was down-regulated in GC cancer tissues. Clinicopathological analysis showed that miR-215 expression level was correlated with the progression of tumor invasion and TNM stage. Additionally, transwell invasion assay showed that miR-215 promoted the migration and invasion of gastric cancer cells. We found that miR-215 decreased FOXO1 expression by directly binding to the 3 '-untranslated region (UTR) of FOXO1. These results suggest that miR-215 promotes cell migration and invasion of gastric cancer by targeting FOXO1. Therefore, this study provides a promising therapeutic strategy for treating gastric cancer.
\end{abstract}

Key words: gastric cancer, miR-215, FOXO1, migration, invasion

Gastric cancer (GC) is one of the most common malignant tumor worldwide and the second leading cause of cancer-related deaths [1]. GC has the highest incidence rate in Eastern Asia, especially in China $[1,2]$. Usually, it is difficult to be diagnosed in the early stage of this disease and most patients are diagnosed in advanced stages, resulting in poor 5-year survival rates [3]. Therefore, finding the new diagnostic or prognostic markers and therapeutic targets to improve the identification of the pathogenic mechanisms involved in GC is necessary.

microRNAs (miRNAs) are small, non-coding RNAs containing $\sim 19-25$ nucleotides [4]. miRNAs play critical roles in the post-transcriptional regulation of gene expression. Usually, the mature miRNAs lead to the translational repression or degradation of the target mRNAs through perfect or imperfect binding to the 3'-untranslated region (3'-UTR) of the target mRNAs [5]. A number of miRNAs have been demonstrated to participate in the tumourigenesis and progression of multiple tumors including GC via regulating several target genes [6-9]. Most miRNAs play critical roles in regulating cell proliferation, migration, invasion, differentiation.

Forkhead BoxO1 (FOXO1) belongs to the forkhead box $\mathrm{O}$ (FOXO) subfamily of transcription factors which are characterized by a conserved forkhead DNA binding domain [10]. FOXO1 is known as a tumor suppressor and involved in a variety of biological progress, such as cell cycle, proliferation, differentiation, metastasis and apoptosis [11-15]. Several studies have demonstrated that FOXO1 is down-regulated in various types of cancer, including GC [12, 16-19]. It has been reported that several miRNAs appear to be involved in the regulation of FOXO1, such as miR-135a, miR-582-5p, miR-182, miR-370, miR-96 [11, 19-22]. However, the regulation of FOXO1 by miRNAs remains still unclear in gastric carcinogenesis.

In this study, we determined the expression level of miR-215 and FOXO1 in gastric cancer tissues and the corresponding noncancerous normal gastric mucosa tissues. We found that miR-215 was frequently up-regulated and FOXO1 was downregulated in GC cancer tissues. And then we detected the 
effect of miR-215 on cell migration and invasion of gastric cancer cells. We reported that overexpression of miR-215 in GC cells decreased FOXO1 protein levels, whereas depletion of miR-215 increased FOXO1 protein levels. Luciferase reporter assay showed that FOXO1 was the target of miR-215. Therefore, these results indicated that over-expressed miR-215 increased GC cell migration and invasion through directly targeting FOXO1.

\section{Materials and methods}

Cell culture. The human GC cell lines AGS, BGC-823, SGC-7901, HGC-27, MGC-803, GES-1(from the Cell Resource Center, Institute of Biochemistry and Cell Biology at the Chinese Academy of Sciences, Shanghai, PR China) were used. AGS cells were cultured in F12 medium (Gibco BRL, Carlsbad, CA, USA) supplemented with $10 \%$ fetal bovine serum (Gibco BRL, Carlsbad, CA, USA), $100 \mathrm{U} / \mathrm{mL}$ penicillin and $100 \mu \mathrm{g} /$ mL streptomycin. BGC-823, SGC-7901, HGC-27, MGC-803, GES-1 cells were cultured in RPMI-1640 medium (Gibco BRL, Carlsbad, CA, USA) with the same supplements. All of the cells were incubated at $37^{\circ} \mathrm{C}$ in $5 \% \mathrm{CO}_{2}$.

Patients. We obtained fresh tumor specimens and surrounding normal tissues from patients with primary GC who underwent gastrectomy at our hospital from 2011 to 2015 . Samples were stored at $-80^{\circ} \mathrm{C}$. No patients had received any adjuvant treatment before the surgery. Clinicopathological characteristics of patients were collected from medical records and all patients provided written informed consent for their tissues to be used in research. This study was approved by the Ethics Committee of Taishan Hospital of Shandong Province.

Cell transfection. X-treme GENE HP Transfection Reagent (Roche Applied Science) was used for the transfection of the plasmids into the GC cells. Lipofectamine 2000 (Invitrogen, Carlsbad, CA, USA) was used to transfect siRNA, miRNA mimics or miRNA inhibitor into the GC cells. All of the transfection procedures followed the manufacturer's instructions.

RNA extraction and qRT-PCR. Total RNAs was isolated from the cells and tissue specimens with TRIzol Reagent (Invitrogen). The first-strand cDNA was synthesized with random primers (N6) or miRNA-specific primers and M-MLV reverse transcriptase (Ferments). Quantitative real-time PCR (qRTPCR) was performed using the Bio-Rad CFX96TM Real-Time PCR System (Bio-Rad) with the SYBR Green Kit (TaKaRa) according to the manufacturer's instructions. Calculation of the target mRNA or miRNA levels was based on the CT method and normalization to human $\beta_{2}-\mathrm{M}$ or U6 expression. All of the reactions were run in triplicate. Primers for miR-215 and U6 were synthesized from RiBoBio (Guangzhou, China). The PCR primers for FOXO1 and $\beta$-microglobulin $(\beta 2-\mathrm{M})$ were synthesized from Invitrogen.

Western blot. Total proteins from the cells were extracted using RIPA lysis buffer. The protein concentrations were measured using the BCA reagent kit (Merck). The proteins were seperated by SDS-PAGE and were transferred to PVDF membrane. Then, the samples were incubated with primary antibody against FOXO1 (Santa Cruz) at $4{ }^{\circ} \mathrm{C}$ overnight and secondary antibody at room temperature for $1 \mathrm{~h}$, and protein was developed using the chemiluminescence method (ECL, Millipore). $\beta$-actin (Sigma-Aldrich) served as a loading control.

Transwell assay. Cell invasion and migration assays were performed using transwell chambers (pore size of $8 \mu \mathrm{M}$; Costar, Corning, NY) with or without $2 \mathrm{mg} / \mathrm{mL}$ Matrigel (Clontech, Mountain View, CA). Gastric cancer cells with different transfection treatments were harvested and resuspended in serum-free RPMI-1640 medium, and $1 \times 10^{5}$ cells were seeded into the upper 24-well chambers. RPMI1640 medium containing 20\% FBS was added to the lower chambers as a chemoattractant. After $24 \mathrm{~h}$, the cells on the upper surface of the membrane were removed, and the cells on the lower surface were fixed with $100 \%$ methanol, stained with $0.05 \%$ crystal violet and photographed under a microscope. The number of migration cells was counted from three independent experiments.

Luciferase assay. Gastric cancer cells with different transfection treatments were collected $48 \mathrm{~h}$ after transfection and luciferase activity was measured using the Dual-Luciferase Reporter Assay System (Promega, Madison, WI, USA). Renilla luciferase was used for normalization. The transfection experiments were performed in triplicate.

Statistical analysis. Statistical analyses were performed using the Statistical Package for the Social Sciences, version 17.0 (SPSS Inc., Chicago, IL, USA). The differences between the groups were analyzed using Student's t-test or $\chi^{2}$ test. $\mathrm{P}<$ 0.05 was considered to be statistically significant.

\section{Results}

miR-215 is frequently up-regulated in GC. To examine the expression level of miR-215 in gastric cancer, 50 pairs of gastric cancers and the corresponding non-cancerous tissues were quantified by real-time PCR. We found that the expression level of miR-215 was significantly up-regulated in 39/50(78\%) of the clinical GC specimens (Figure 1A) and the average expression level of miR-215 in tumor tissues was significantly higher than that in surrounding non-cancerous tissues $(\mathrm{P}<0.0001$; Figure 1B). Clinicopathological analysis showed that miR-215 expression level was correlated with the progression of tumor invasion and TNM stage (Table 1). In addition, the miR-215 expression in the 5 GC cell lines (AGS, BGC-823, SGC-7901, HGC-27, MGC-803) was also markedly up-regulated, compared with normal gastric epithelial GES-1 cells (Figure 1C).

Additionally, we used real-time PCR to detect the expression level of FOXO1 in 50 pairs of gastric cancers and the corresponding non-cancerous tissues, found that FOXO1 was down-regulated in GC (Figure 1D). Statistical analysis 

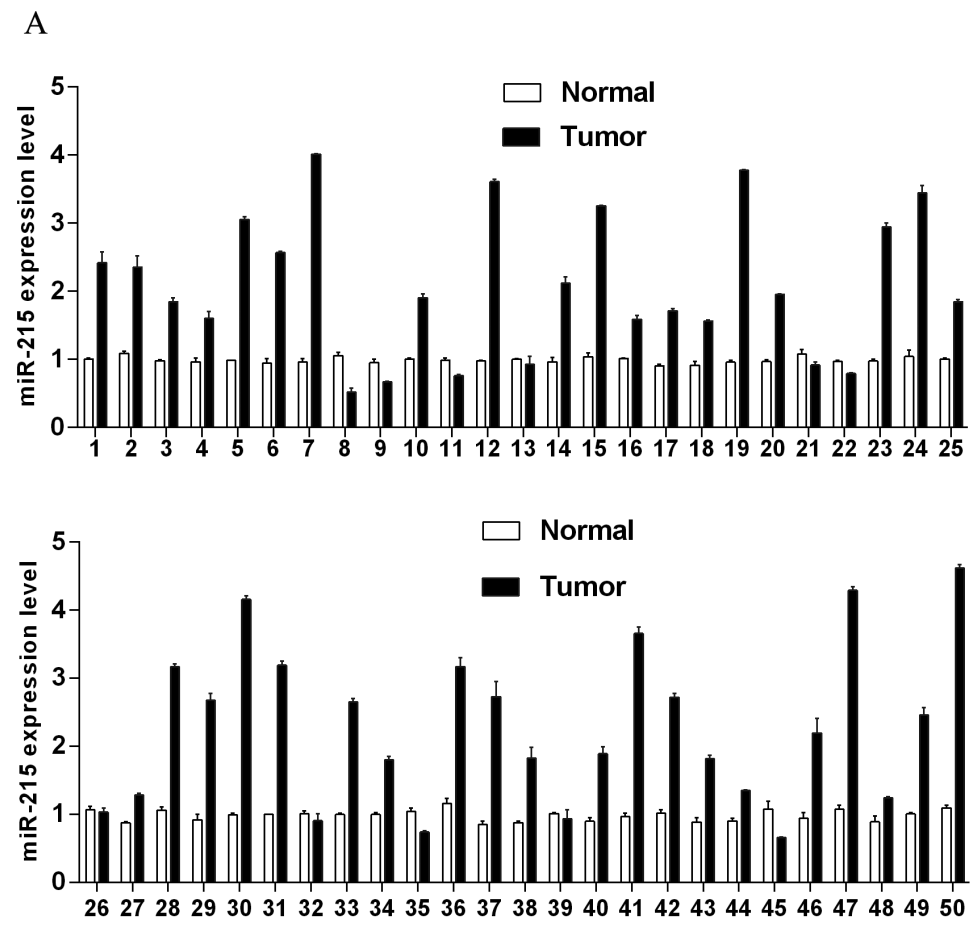

B

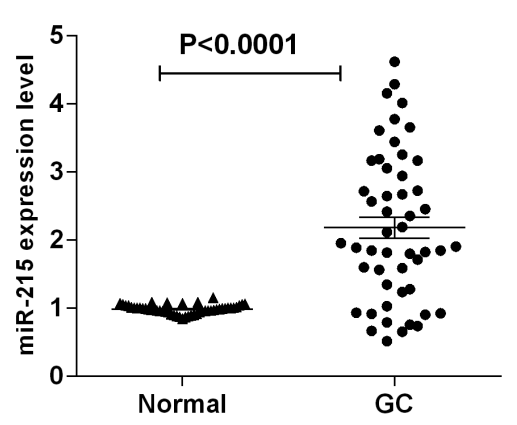

$\mathrm{D}$

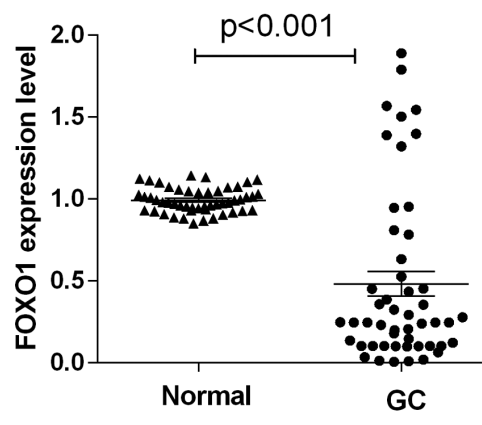

$\mathrm{E}$
$\mathrm{C}$
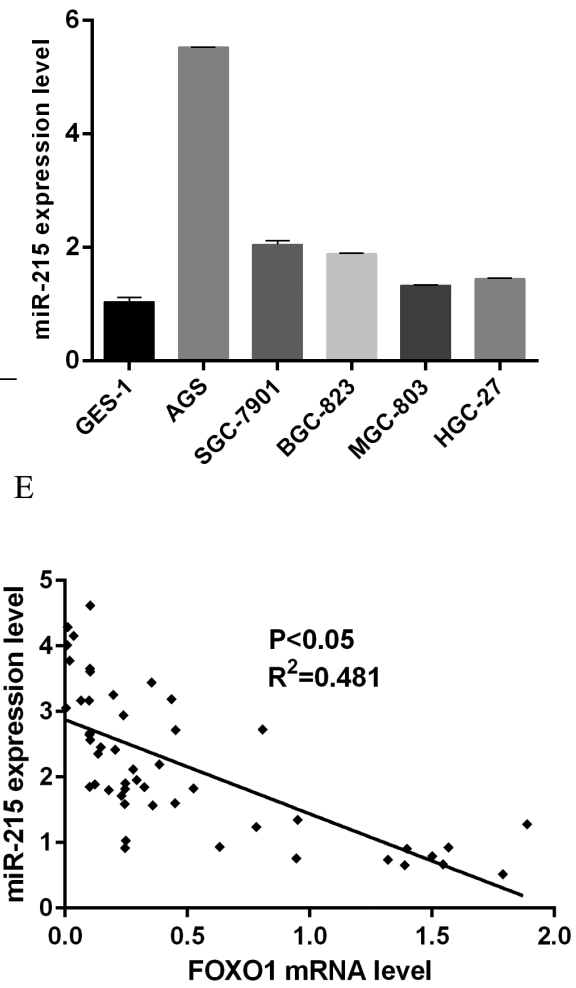

Figure 1: miR-215 was frequently up-regulated and FOXO1 was down-regulated in GC (A) qRT-PCR analysis of the miR-215 expression level in 50 paired human GC and adjacent normal gastric mucosa tissues. The data are expressed as the means \pm SD from three repeats. (B) Quantitative analysis of miR-215 expression in GC tissues and adjacent normal gastric mucosa $(n=50, P<0.0001)$. Horizontal lines represent the means \pm SD. (C) $q R T-P C R$ analysis of the miR-215 expression level in various gastric cancer cells compared with normal gastric epithelial cell line GES-1. (D) qRT-PCR analysis of the FOXO1 expression level in 50 paired human GC and adjacent normal gastric mucosa tissues. (E) Regression analysis of correlation of miR-215 and FOXO1 expression. Each point represents one cancer sample. 
showed that miR-215 expression was negatively associated with FOXO1 in the GC samples (Figure 1E).

miR-215 promotes migration and invasion of GC cell. To investigate the function of miR-215 in gastric cancer cells, we transiently transfected the miR-215 mimics into GES-1 cell or inhibitor into the AGS cells. The transfection efficiency was verified by qRT-PCR (Figure 2A, 2B). The transwell assays were used to detect the effect of the miR-215 mimics or inhibitor on cell migration and invasion. The results showed that miR-215 mimics promoted cell migration and invasion in GES-1 cells (Figure 2C, 2D), whereas its inhibitor reduced cell migration and invasion (Figure 2E, 2F) in AGS cell, respectively.

miR-215 directly targets FOXO1 3'-UTR and decreases FOXO1 expression. It has been well documented that miRNAs play an important roles in the regulation of gene expression mainly through binding to the 3'-UTR of target mRNA. We used different databases such as TargetScan, Mirnada and miRBase to predict the targets of miR-215 and found FOXO1 might be targeted by miR-215. Bioinformatics analysis revealed that there was one putative miR-215 binding site in the nucleotide sequence from 1715 to 1721

Table 1. miR-215 expression and clinicopathological features in 50 paired gastric cancer

\begin{tabular}{|c|c|c|c|}
\hline \multicolumn{4}{|c|}{ miR-215 expression } \\
\hline variable & $\begin{array}{l}\text { Up-regulated } \\
\quad(n=39)\end{array}$ & $\begin{array}{l}\text { Down-regulated } \\
\quad(\mathrm{n}=11)\end{array}$ & p-value \\
\hline \multicolumn{4}{|l|}{ Age(years) } \\
\hline$\leq 60$ & 22 & 8 & 0.4895 \\
\hline$>60$ & 17 & 3 & \\
\hline \multicolumn{4}{|l|}{ Gender } \\
\hline Male & 16 & 4 & 1.0000 \\
\hline Female & 23 & 7 & \\
\hline \multicolumn{4}{|l|}{ Tumor(cm) } \\
\hline$<5$ & 24 & 6 & 0.7359 \\
\hline$\geq 5$ & 15 & 5 & \\
\hline \multicolumn{4}{|c|}{ Differentiation } \\
\hline Well & 12 & 0 & 0.0829 \\
\hline Moderate & 13 & 3 & \\
\hline Low & 14 & 8 & \\
\hline \multicolumn{4}{|c|}{ Local invasion } \\
\hline $\mathrm{T} 1, \mathrm{~T} 2$ & 10 & 8 & 0.0039 \\
\hline $\mathrm{T} 3, \mathrm{~T} 4$ & 29 & 3 & \\
\hline \multicolumn{4}{|c|}{ Distant metastasis } \\
\hline M0 & 9 & 7 & 0.0241 \\
\hline M1 & 30 & 4 & \\
\hline \multicolumn{4}{|l|}{ TNM stage } \\
\hline I, II & 11 & 9 & 0.0036 \\
\hline III, IV & 28 & 2 & \\
\hline
\end{tabular}

of FOXO1 3'-UTR (Figure 3A). Therefore, we transfected the miR-215 mimics or inhibitor in GC cells and used qRT-PCR and western blotting to determine the effect of miR-215 on the expression of FOXO1. The results showed that ectopic expression of miR-215 significantly decreased the expression of FOXO1 at protein and mRNA levels in AGS cell lines (Figure 3B, 3C). Moreover, the inhibition of endogenous miR- 215 by the miR-215 inhibitor significantly increased the protein and mRNA levels of FOXO1 in AGS cells (Figure 3B, 3C).

To determine whether FOXO1 is directly targeted by miR215 in GC cells, we constructed luciferase reporter vector containing wild-type (WT) or mutant (Mut) seed regions of FOXO1. AGS cell was cotransfected with WT or Mut 3'-UTR luciferase reporters and miR-215 mimics. The luciferase activity was determined at $48 \mathrm{~h}$ post transfection. As shown in Figure 3D, ectopic expression of miR-215 decreased luciferase activity in cells transfected with wild-type FOXO1 3'-UTR and had no effect on luciferase activity in cells expressing with mutant FOXO1 3'-UTR reporter in AGS cell lines. These results suggested that FOXO1 was a direct target of miR-215 in GC cells.

Depletion of FOXO1 could reverse partial function of miR-215. A number of evidences demonstrated that FOXO1 plays critical roles in the migration and invasion. Our data suggested that inhibition of miR-215 decreased GC cell migration and invasion. Next, we used FOXO1specific siRNA to knockdown FOXO1 expression in AGS cells. The transfection efficiency of FOXO1 siRNA in GC cell was shown in Figure 4A, 4B. The transwell assay results showed that knockdown of FOXO1 increased the migration and invasion in AGS cells (Figure 4C, 4D). FOXO1 siRNA deprived miR-215 inhibitor-mediated inhibition of cell migration and invasion, suggesting that FOXO1 is involved in the miR-215-mediated biological role in gastric cancer cells (Figure 4E, 4F). Therefore, depletion of FOXO1 could reverse partial function of miR-215.

\section{Discussion}

GC remains one of the most frequently occurring malignancies worldwide and the prognosis of GC is very poor. Thus, further understanding the molecular mechanisms of GC is necessary. microRNAs (miRNAs) are important epigenetic regulators participating in the development and progression of various cancers types, including GC [23-25]. miRNAs act as oncogenes or tumor suppressors in tumors [24, 26-29]. It has been reported that miR-215 plays important roles in a variety of tumor cancer. Previous studies showed that miR-215 was down-regulated in several cancers, such as, colon cancer [30], breast cancer [31], and lung cancer [32]. However, in this current study, we found that miR-215 is frequently up-regulated in GC and the average expression level of miR-215 in tumor tissues was significantly higher than that in surrounding non-cancerous tissues. This 
A
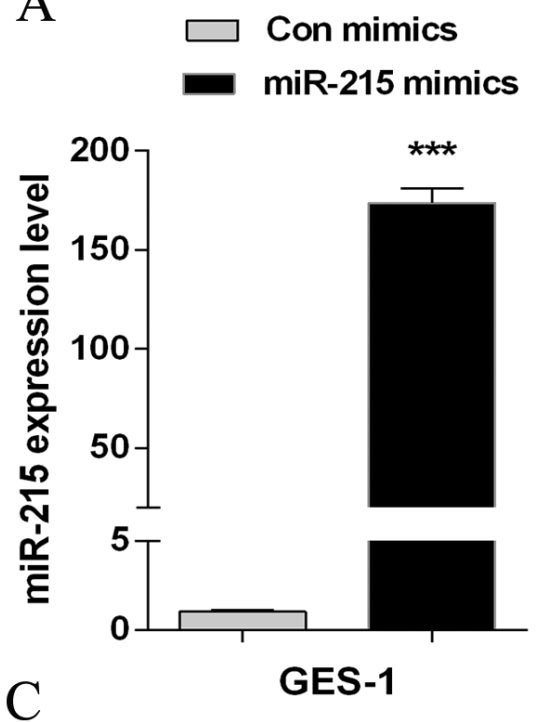

C

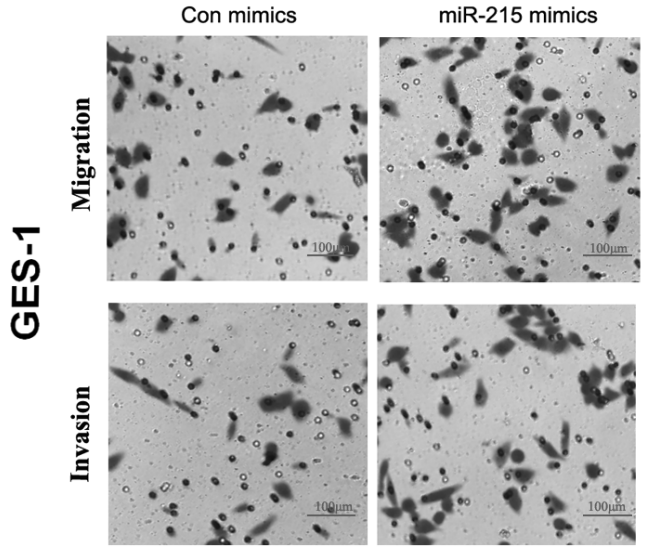

E

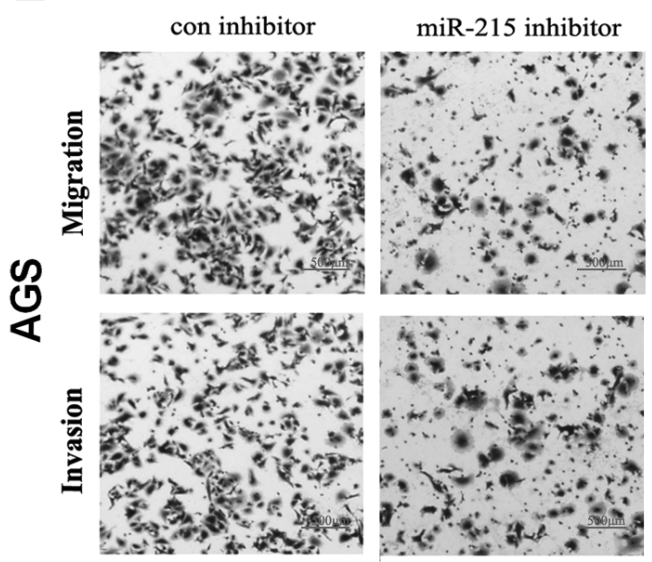

$\mathrm{B}$

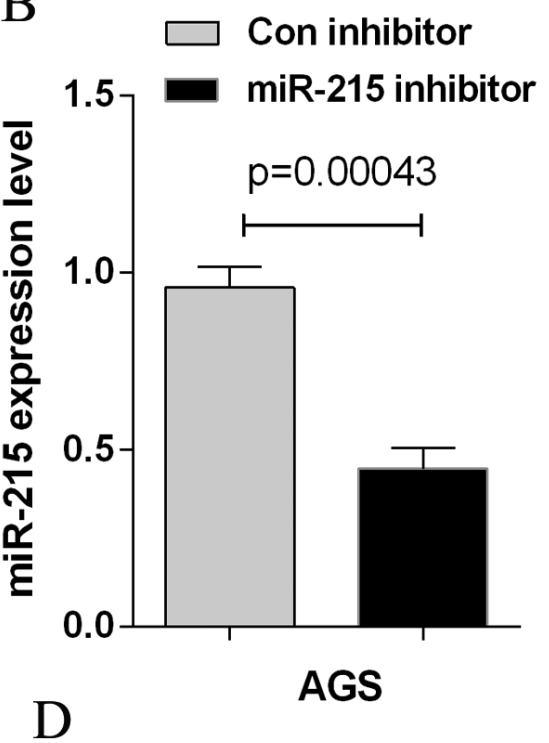

$\mathbf{D}$

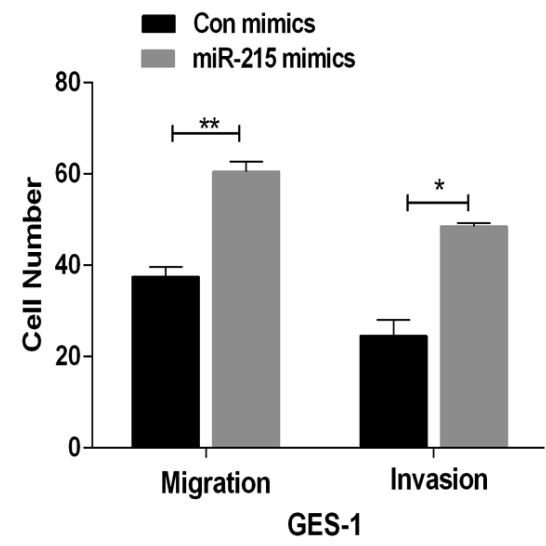

$\mathbf{F}$

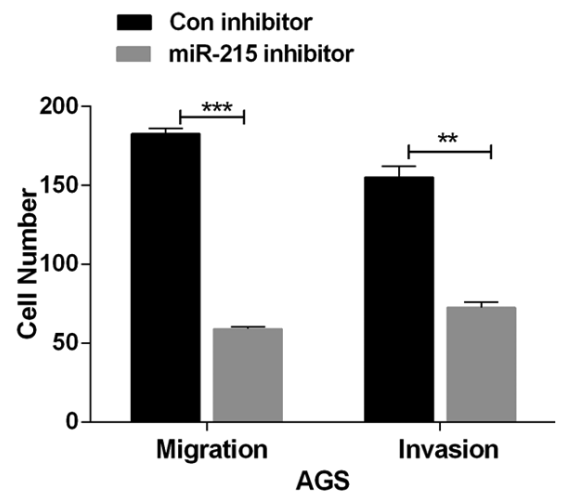

Figure 2. miR-215 promoted migration and invasion of GC cell (A) QRT-PCR analysis of the miR-215 expression level in GES-1 cells transfected with control mimics and miR-215mimics. (B) qRT-PCR analysis of the miR-215 expression level in AGS cell transfected with control inhibitor and miR-215 inhibitor. (C) Transwell migration and invasion assay. GES-1 cells were transfected with the control or miR-215 mimics. (D) Quantitative analysis of the migration and invasion number in GES-1 cells transfected with miR-215 mimics. The data are expressed as the means \pm SD from three experiments. (E) Transwell migration and invasion assays. AGS cells was transfected with the control or miR-215 inhibitor. (F) Quantitative analysis of the migration and invasion number in AGS cells transfected with miR-215 inhibitor. The data are expressed as the means \pm SD from three experiments. ${ }^{\star} P<0.05$, ${ }^{* *} \mathrm{P}<0.01,{ }^{* * *} \mathrm{P}<0.001$. 
A

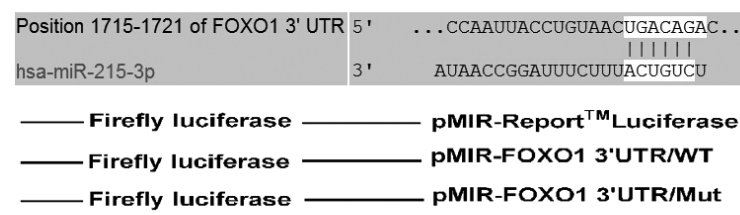

B

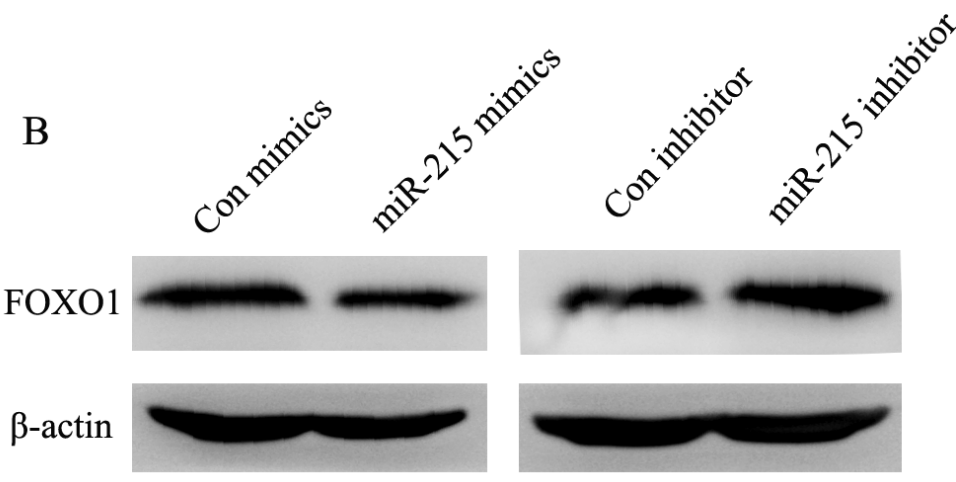

$\mathrm{C}$

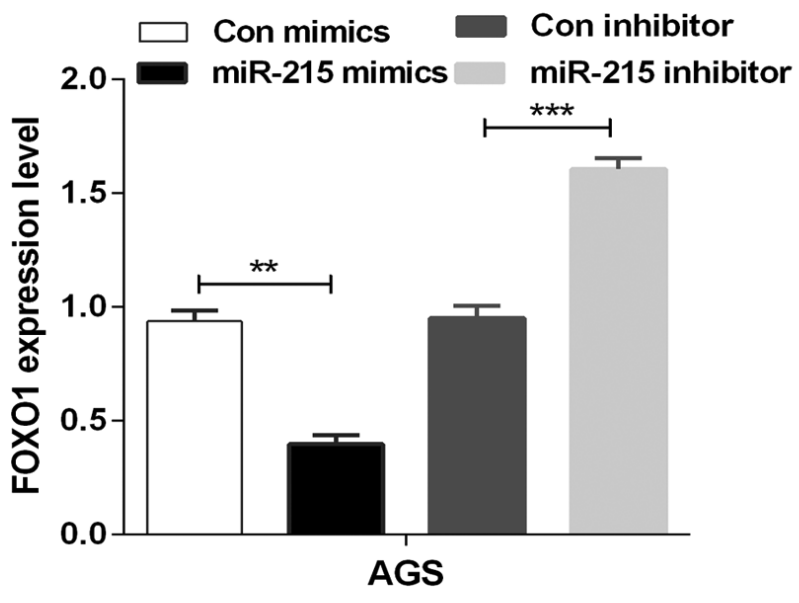

D

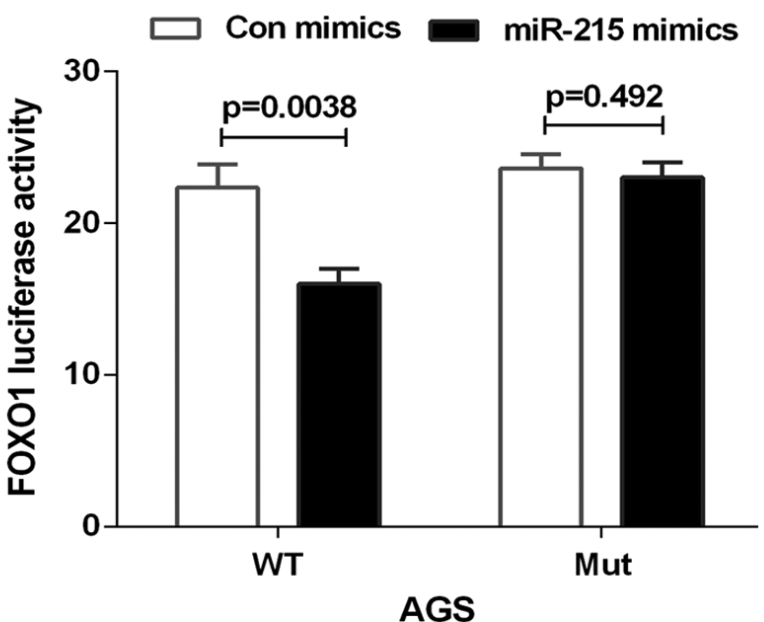

Figure 3. miR-215 de-regulated FOXO1 expression by directly binding to the 3'-UTR of FOXO1. (A) Upper: The putative miR-215 binding sequence in the 3'-UTR of FOXO1. Lower: FOXO1 3'-UTR fragment containing either the wild type (WT) or mutant (Mut) miR-215 binding sequences was cloned downstream of the luciferase reporter. (B) Western blot analysis of the expression level of FOXO1 in AGS cells transfected with the control and miR215 mimics or the control and miR-215 inhibitor. (C) qRT-PCR analysis of the FOXO1 mRNA level in AGS cells transfected with control and miR-215 mimics or the control and miR-215 inhibitor. (D) Analysis of luciferase activity. The wild-type or mutant reporter constructs were co-transfected with control or miR-215 mimics into AGS cells. Firefly luciferase activity was normalized to Renilla. ${ }^{* *} P<0.01,{ }^{* * *} P<0.001$.

is consistent with previous studies [33, 34]. Moreover, miR215 expression level was correlated with the progression of tumor invasion and TNM stage.

Since miR-215 is frequently up-regulated in gastric cancer, we tried to explore the biological functions of miR-215 in GC. In this study, we confirmed that miR-215 could promote the migration and invasion in GC cells. miR-215 mimics facilitated cell migration and invasion, whereas, miR-215 inhibitor reduced cell migration and invasion. Furthermore, we first identified FOXO1 as a novel direct target of miR-215 in GC cells using luciferase assay.

Forkhead box protein O1 (FOXO1), is a member of the FOXO family of transcription factors, functions as a tumor suppressor and involves in a variety of biological processes $[35,36]$. There are reports showing that FOXO1 was downregulated in some human cancers, including GC [12]. Several
miRNAs were involved in the regulation of FOXO1. For exam$\mathrm{ple}, \mathrm{Xu}$ et al. found that FOXO1 is a direct target of miR-135b and down-regulation of miR-135b could inhibit growth of cervical cancer cells and decrease proliferation and invasion of osteosarcoma cells via targeting FOXO1 [37, 38]. Besides, Mao et al [11] and Guo et al [22] have demonstrated that miR-135a and miR-96 directly target FOXO1 and regulate FOXO1 protein expression in bladder cancer. Down-regulation of miR-135a or miR-96 leads to the up-regulation of FOXO1 protein. The downregulation of FOXO1 in prostate cancer cells and gastric cancer cells inhibit the migration and invasion [12, 39]. In this study, we found that the expression level of FOXO1 in GC tumor was significantly lower than that in surrounding non-cancerous tissues. Statistical analysis showed that miR-215 expression was negatively associated with FOXO1 in the GC samples. Furthermore, we confirmed the biologi- 
A

AGS

Con siRNA FOXO1 siRNA

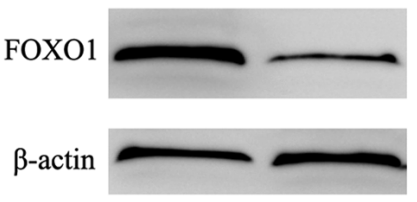

$\mathrm{B}$

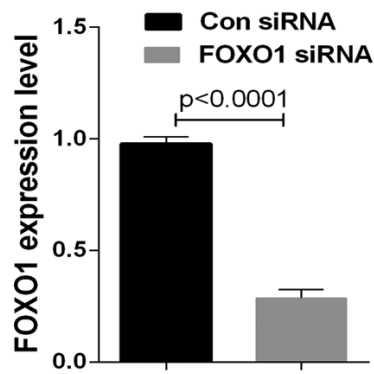

$\mathrm{C}$

\section{AGS}

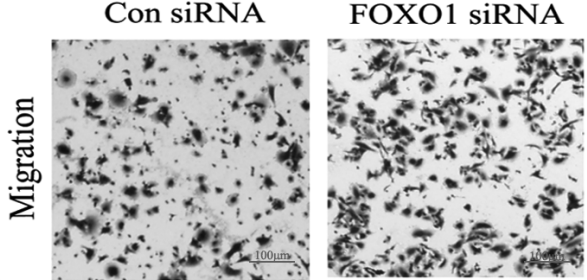

$\mathrm{D}$

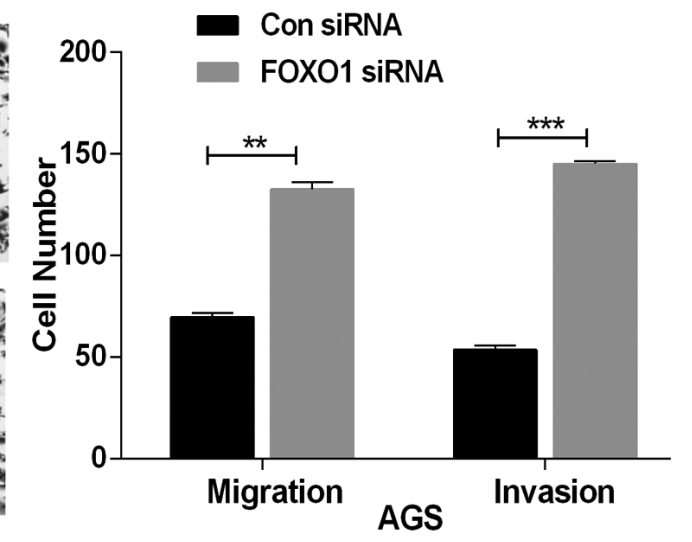

$\mathrm{E}$

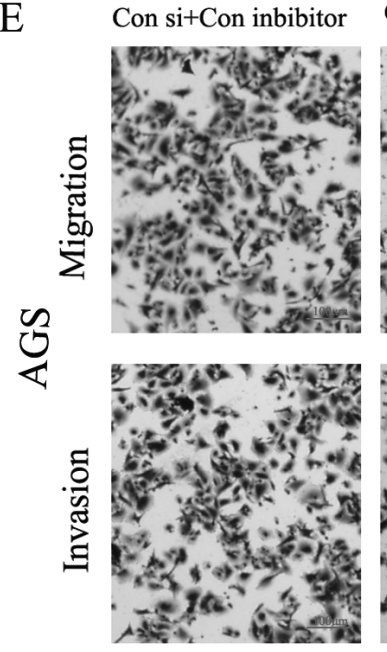

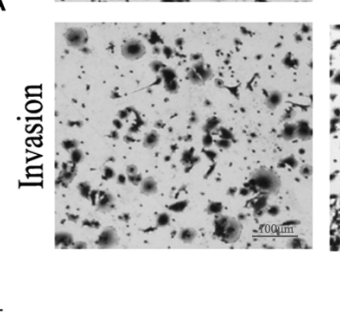

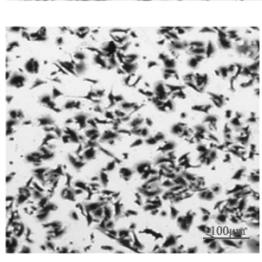

Figure 4. Depletion of FOXO1 could reverse partial function of miR-215

Western blot (A) and qRT-PCR (B) analysis of the FOXO1 expression level in AGS cells transfected with Control siRNA (Con siRNA) or FOXO1 siRNA. The results confirmed the transfection efficiency. (C) Transwell assay of the migration and invasion ability of AGS cells transfected with Con siRNA or FOXO1 siRNA. (D) Quantitative analysis of the migration and invasion number in AGS cells transfected with FOXO1 siRNA. The data are expressed as the means \pm SD from three experiments. (E) Transwell assay of the migration and invasion and quantitative analysis (F) of AGS cells co-transfected with miR-215 inhibitor (215 inhibitor) and FOXO1 siRNA (FOXO1 si) or the Control (Control siRNA or Control inhibitor). ${ }^{* *} P<0.01,{ }^{* * *} P<0.001$.

cal role of FOXO1 in gastric cancer and found that deletion of FOXO1 could inhibit the migration and invasion of GC cells. This is consistent with previous study that demonstrated FOXO1 shRNA significantly increased migration and invasion compared with their respective controls [12]. Additionally, we found that depletion of FOXO1 could reverse partial function of miR-215 (Figure4).

In conclusion, our results suggest that miR-215 is frequently up-regulated and negatively associated with FOXO1 in gastric cancer. Moreover, the over-expression of miR-215 promotes the migration and invasion of GC cells by directly targeting FOXO1. Thus, these findings indicate that miR-215 may be a potential diagnostic marker and a novel therapeutic target of gastric cancer.

\section{References}

[1] JEMAL A, BRAY F, CENTER MM, FERLAY J, WARD E et al. Global cancer statistics. CA Cancer J Clin 2011; 61: 69-90. https://doi.org/10.3322/caac.20107 
[2] BERTUCCIO P, CHATENOUD L, LEVI F, PRAUD D, FERLAY J et al. Recent patterns in gastric cancer: a global overview. Int J Cancer 2009; 125: 666-673. https://doi.org/10.1002/ ijc. 24290

[3] CORREA P. Is gastric cancer preventable? Gut 2004; 53: 1217-1219. https://doi.org/10.1136/gut.2004.039834

[4] BARTEL DP. MicroRNAs: genomics, biogenesis, mechanism, and function. Cell 2004; 116: 281-297. https://doi. org/10.1016/S0092-8674(04)00045-5

[5] HE L and HANNON GJ. MicroRNAs: small RNAs with a big role in gene regulation. Nat Rev Genet 2004; 5: 522-531. https://doi.org/10.1038/nrg1379

[6] CALIN GA and CROCE CM. MicroRNA signatures in human cancers. Nat Rev Cancer 2006; 6: 857-866. https://doi. org/10.1038/nrc1997

[7] NEGRINI M, NICOLOSO MS and CALIN GA. MicroRNAs and cancer--new paradigms in molecular oncology. Curr Opin Cell Biol 2009; 21: 470-479. https://doi.org/10.1016/j. ceb.2009.03.002

[8] VOLINIA S, CALIN GA, LIU CG, AMBS S, CIMMINO A et al. A microRNA expression signature of human solid tumors defines cancer gene targets. Proc Natl Acad Sci U S A 2006; 103: 2257-2261. https://doi.org/10.1073/pnas.0510565103

[9] WU WK, LEE CW, CHO CH, FAN D, WU K et al. MicroRNA dysregulation in gastric cancer: a new player enters the game. Oncogene 2010; 29: 5761-5771. https://doi.org/10.1038/ onc. 2010.352

[10] CALNAN DR and BRUNET A. The FoxO code. Oncogene 2008; 27: 2276-2288. https://doi.org/10.1038/onc.2008.21

[11] MAO XP, ZHANG LS, HUANG B, ZHOU SY, LIAO J et al. Mir-135a enhances cellular proliferation through post-transcriptionally regulating PHLPP2 and FOXO1 in human bladder cancer. J Transl Med 2015; 13: 86. https://doi. org/10.1186/s12967-015-0438-8

[12] KO YS, CHO SJ, PARK J, KIM Y, CHOI YJ et al. Loss of FOXO1 promotes gastric tumour growth and metastasis through upregulation of human epidermal growth factor receptor 2/neu expression. Br J Cancer 2015; 113: 1186-1196. https://doi.org/10.1038/bjc.2015.273

[13] NAKAMURA N, RAMASWAMY S, VAZQUEZ F, SIGNORETTI S, LODA $M$ et al. Forkhead transcription factors are critical effectors of cell death and cell cycle arrest downstream of PTEN. Mol Cell Biol 2000; 20: 8969-8982. https://doi. org/10.1128/MCB.20.23.8969-8982.2000

[14] HUANG H and TINDALL DJ. Dynamic FoxO transcription factors. J Cell Sci 2007; 120: 2479-2487. https://doi. org/10.1242/jcs.001222

[15] XIE L, USHMOROV A, LEITHAUSER F, GUAN H, STEIDL C et al. FOXO1 is a tumor suppressor in classical Hodgkin lymphoma. Blood 2012; 119: 3503-3511. https://doi.org/10.1182/ blood-2011-09-381905

[16] GUTTILLA IK and WHITE BA. Coordinate regulation of FOXO1 by miR-27a, miR-96, and miR-182 in breast cancer cells. J Biol Chem 2009; 284: 23204-23216. https://doi. org/10.1074/jbc.M109.031427

[17] KIM TH, JO SW, LEE YS, KIM YJ, LEE SC et al. Forkhead box $\mathrm{O}$-class 1 and forkhead box G1 as prognostic markers for bladder cancer. J Korean Med Sci 2009; 24: 468-473. https:// doi.org/10.3346/jkms.2009.24.3.468

[18] MYATT SS, WANG J, MONTEIRO LJ, CHRISTIAN M, HO KK et al. Definition of microRNAs that repress expression of the tumor suppressor gene FOXO1 in endometrial cancer. Cancer Res 2010; 70: 367-377. https://doi.org/10.1158/00085472.CAN-09-1891

[19] WALLIS CJ, GORDANPOUR A, BENDAVID JS, SUGAR L, NAM RK et al. MiR-182 Is Associated with Growth, Migration and Invasion in Prostate Cancer via Suppression of FOXO1. J Cancer 2015; 6: 1295-1305. https://doi.org/10.7150/jca.13176

[20] LIU Y, JIANG J, WANG X, ZHAI F AND CHENG X. miR$582-5 p$ is upregulated in patients with active tuberculosis and inhibits apoptosis of monocytes by targeting FOXO1. PLoS One 2013; 8: e78381. https://doi.org/10.1371/journal. pone.0078381

[21] WU Z, SUN H, ZENG W, HE J AND MAO X. Upregulation of MircoRNA-370 induces proliferation in human prostate cancer cells by downregulating the transcription factor FOXO1. PLoS One 2012; 7: e45825. https://doi.org/10.1371/journal. pone. 0045825

[22] GUO Y, LIU H, ZHANG H, SHANG C and SONG Y. miR96 regulates FOXO1-mediated cell apoptosis in bladder cancer. Oncol Lett 2012; 4: 561-565. https://doi.org/10.3892/ $\underline{\mathrm{ol} .2012 .775}$

[23] IORIO MV and CROCE CM. MicroRNAs in cancer: small molecules with a huge impact. J Clin Oncol 2009; 27: 58485856. https://doi.org/10.1200/JCO.2009.24.0317

[24] JIANG C, CHEN X, ALATTAR M, WEI J and LIU H. MicroRNAs in tumorigenesis, metastasis, diagnosis and prognosis of gastric cancer. Cancer Gene Ther 2015; 22: 291-301. https:// doi.org/10.1038/cgt.2015.19

[25] LU J, GETZ G, MISKA EA, ALVAREZ-SAAVEDRA E, LAMB J et al. MicroRNA expression profiles classify human cancers. Nature 2005; 435: 834-838. https://doi.org/10.1038/ nature 03702

[26] DUAN J, ZHANG H, QU Y, DENG T, HUANG D et al. Onco-miR-130 promotes cell proliferation and migration by targeting TGFbetaR2 in gastric cancer. Oncotarget 2016;

[27] ESQUELA-KERSCHER A and SLACK FJ. Oncomirs - microRNAs with a role in cancer. Nat Rev Cancer 2006; 6: 259-269. https://doi.org/10.1038/nrc1840

[28] FABBRI M, GARZON R, CIMMINO A, LIU Z, ZANESI N et al. MicroRNA-29 family reverts aberrant methylation in lung cancer by targeting DNA methyltransferases $3 \mathrm{~A}$ and $3 \mathrm{~B}$. Proc Natl Acad Sci U S A 2007; 104: 15805-15810. https://doi. org/10.1073/pnas.0707628104

[29] HE L, THOMSON JM, HEMANN MT, HERNANDOMONGE E, MU D et al. A microRNA polycistron as a potential human oncogene. Nature 2005; 435: 828-833. https://doi.org/10.1038/nature03552

[30] LI S, GAO J, GU J, YUAN J, HUA D et al. MicroRNA-215 inhibits relapse of colorectal cancer patients following radical surgery. Med Oncol 2013; 30: 549. https://doi.org/10.1007/ s12032-013-0549-0

[31] ZHOU SW, SU BB, ZHOU Y, FENG YQ, GUO Y et al. Aberrant miR-215 expression is associated with clinical outcome 
in breast cancer patients. Med Oncol 2014; 31: 259. https:// doi.org/10.1007/s12032-014-0259-2

[32] HOU Y, ZHEN J, XU X, ZHEN K, ZHU B et al. miR-215 functions as a tumor suppressor and directly targets ZEB2 in human non-small cell lung cancer. Oncol Lett 2015; 10: 1985-1992. https://doi.org/10.3892/ol.2015.3587

[33] DENG Y, HUANG Z, XU Y, JIN J, ZHUO W et al. MiR-215 modulates gastric cancer cell proliferation by targeting RB1. Cancer Lett 2014; 342: 27-35. https://doi.org/10.1016/j.canlet.2013.08.033

[34] JIN Z, SELARU FM, CHENG Y, KAN T, AGARWAL R et al. MicroRNA-192 and -215 are upregulated in human gastric cancer in vivo and suppress ALCAM expression in vitro. Oncogene 2011; 30: 1577-1585. https://doi.org/10.1038/ onc. 2010.534

[35] FENG X, WU Z, WU Y, HANKEY W, PRIOR TW et al. $\mathrm{Cdc} 25 \mathrm{~A}$ regulates matrix metalloprotease 1 through Foxo 1 and mediates metastasis of breast cancer cells. Mol Cell Biol
2011; 31: 3457-3471. https://doi.org/10.1128/MCB.05523$\underline{11}$

[36] KIM SY, KO YS, PARK J, CHOI Y, PARK JW et al. Forkhead Transcription Factor FOXO1 Inhibits Angiogenesis in Gastric Cancer in Relation to SIRT1. Cancer Res Treat 2016; 48: 345-354. https://doi.org/10.4143/crt.2014.247

[37] XU Y, ZHAO S, CUI M and WANG Q. Down-regulation of microRNA-135b inhibited growth of cervical cancer cells by targeting FOXO1. Int J Clin Exp Pathol 2015; 8: 10294-10304.

[38] PEI H, JIN Z, CHEN S, SUN X, YU J et al. MiR-135b promotes proliferation and invasion of osteosarcoma cells via targeting FOXO1. Mol Cell Biochem 2015; 400: 245-252. https://doi. org/10.1007/s11010-014-2281-2

[39] ZHANG H, PAN Y, ZHENG L, CHOE C, LINDGREN B et al. FOXO1 inhibits Runx2 transcriptional activity and prostate cancer cell migration and invasion. Cancer Res 2011; 71: 3257-3267. https://doi.org/10.1158/0008-5472.CAN-10-2603 